\title{
Friction Stir Processing of Magnesium Alloys: A Review
}

\author{
Wen Wang ${ }^{1,2,3} \cdot$ Peng Han ${ }^{1,2} \cdot$ Pai Peng ${ }^{1,2} \cdot$ Ting Zhang $^{1,2}$. Qiang Liu ${ }^{1,2} \cdot$ Sheng-Nan Yuan ${ }^{1,2} \cdot$ Li-Ying Huang $^{1,2}$. \\ Hai-Liang Yu ${ }^{4} \cdot \mathrm{Ke} \mathrm{Qiao}^{1,2} \cdot$ Kuai-She Wang ${ }^{1,2}$
}

Received: 9 April 2019 / Revised: 12 July 2019 / Published online: 2 December 2019

(c) The Chinese Society for Metals (CSM) and Springer-Verlag GmbH Germany, part of Springer Nature 2019

\begin{abstract}
Magnesium (Mg) alloys have been extensively used in various fields, such as aerospace, automobile, electronics, and biomedical industries, due to their high specific strength and stiffness, excellent vibration absorption, electromagnetic shielding effect, good machinability, and recyclability. Friction stir processing (FSP) is a severe plastic deformation technique, based on the principle of friction stir welding. In addition to introducing the basic principle and advantages of FSP, this paper reviews the studies of FSP in the modification of the cast structure, superplastic deformation behavior, preparation of finegrained Mg alloys and Mg-based surface composites, and additive manufacturing. FSP not only refines, homogenizes, and densifies the microstructure, but also eliminates the cast microstructure defects, breaks up the brittle and network-like phases, and prepares fine-grained, ultrafine-, and nano-grained Mg alloys. Indeed, FSP significantly improves the comprehensive mechanical properties of the alloys and achieves low-temperature and/or high strain rate superplasticity. Furthermore, FSP can produce particle- and fiber-reinforced $\mathrm{Mg}$-based surface composites. As a promising additive manufacturing technique of light metals, FSP enables the additive manufacturing of Mg alloys. Finally, we prospect the future research direction and application with friction stir processed Mg alloys.
\end{abstract}

Keywords Friction stir processing $\cdot$ Magnesium alloy $\cdot$ Superplasticity $\cdot$ Grain refinement $\cdot$ Mg-based surface composites · Additive manufacturing

\section{Introduction}

Magnesium ( $\mathrm{Mg}$ ) alloys have been widely used in various fields, such as aerospace, automobile, electronics, and biomedical industries, owing to their high specific strength and stiffness, excellent vibration absorption, electromagnetic

Available online at http://link.springer.com/journal/40195.

Wen Wang

wangwen2016@126.com

Kuai-She Wang

wangkuaishe888@126.com

1 School of Metallurgical Engineering, Xi' an University of Architecture and Technology, Xi' an 710055, China

2 National and Local Joint Engineering Research Center for Functional Materials Processing, Xi' an 710055, China

3 Experimental Teaching Demonstration Center for Materials Processing, Xi' an University of Architecture and Technology, Xi' an 710055, China

4 College of Mechanical and Electrical Engineering, Central South University, Changsha 410083, China shielding effect, good machinability, and recyclability [1]. With the growing contradiction between resource shortage and sustainable development, $\mathrm{Mg}$ alloys with lightweight and high strength have been attracting increasing interest in recent years [2].

Compared with nonferrous metals, such as aluminum alloys and titanium alloys, the strength of the Mg alloys is relatively lower. Moreover, due to the hexagonal closepacked (HCP) crystal structure of Mg alloys, the plastic deformation at room temperature is mainly dominated by basal slip, whereas prismatic and pyramidal slips are impeded. Even though the prismatic slip occurs as well, the basal and prismatic slips can only provide four independent slip systems, which do not satisfy the requirements of the von Mises criterion. Furthermore, the basal and prismatic slips cannot coordinate the strain along the $c$-axis; therefore, the plasticity of $\mathrm{Mg}$ alloys at room temperature is low, and the plastic forming is difficult. To improve the strength and plasticity of $\mathrm{Mg}$ alloys, grain refinement has been applied.

In 1999, Mishra [3] invented a new severe plastic deformation (SPD) technique: friction stir processing (FSP), 
based on the principle of the friction stir welding (FSW). In this processing, the microstructure of materials can be refined, homogenized, and densified simultaneously, thus improving both the strength and plasticity of materials.

The principle of FSP is similar to that of FSW. Firstly, the tool with a shoulder and a pin rotates into the workpiece. Then, when the pin is completely inserted into the workpiece, and the shoulder is in touch with the surface of the workpiece, the rotating tool travels along the predetermined direction at the same time. Under the synergetic effect of the pin and the shoulder, thermoplastic materials undergo severe plastic deformation, resulting in dynamic recrystallization and significant grain refinement [3]. Ultrafine- and nano-grained materials can be prepared by FSP under forced cooling conditions such as water, dry ice, and alcohol [4]. For example, ultrafine-grained $\mathrm{Mg}$ alloy with a grain size of $100-300 \mathrm{~nm}$ has been successfully prepared by FSP, showing that its strength has been remarkably enhanced $[5,6]$.

As an SPD technique, FSP has the following advantages. Firstly, FSP can refine, homogenize, and densify the microstructure of materials simultaneously. It has been shown that dynamic recrystallization decreases the dislocation density while increasing the fraction of the high-angle grain boundary to $97 \%$ [7]. Such microstructure characteristics ensure that the fine-grained materials have not only high strength but also good plasticity. Secondly, FSP can process the workpiece locally without affecting its shape and size: This processing depth ranges from hundreds of microns to tens of millimeters. The precise control of microstructure and properties can be achieved by the optimization of tool design and process parameters [8]. Thirdly, the process parameters of FSP are easy to control as advanced intelligent FSP equipment can realize the digital forming manufacturing of threedimensional components.

In view of the advantages of FSP, many researchers have focused on the following aspects of friction stir processed (FSPed) Mg alloys: (1) modification of the cast structure by FSP; (2) preparation of the fine-grained, ultrafine-, and nano-grained Mg alloys by FSP; (3) superplastic deformation behavior of FSPed Mg alloys; (4) preparation of Mgbased surface composites by FSP; and (5) FSP additive manufacturing technique. Therefore, this review will focus on the progress of FSPed Mg alloys in the five above-mentioned aspects, providing new insights into their future development and industrial application.

\section{Research Progress}

\subsection{Modification of the Cast Structure}

As most of $\mathrm{Mg}$ alloys for industrial applications are cast structure, casting and solidifying defects, such as pores, inclusions, microcracks, and composition segregation, are inevitable. In particular, brittle and network-like secondary phases of the alloys result in poor plastic deformation. FSP not only reduces and even eliminates these defects but also breaks up the brittle and network-like secondary phases.

During FSP, the secondary phases in the Mg alloys are usually broken and dissolved, thus forming the supersaturated solid solution in the processing zone [9-12]. Feng and $\mathrm{Ma}$ [9] found that FSP led to the fragmentation of the original coarse network-like $\beta-\mathrm{Mg}_{17} \mathrm{Al}_{12}$ phase and its rapid dissolution in cast AZ91 Mg alloy. A similar phenomenon of rapid dissolution of $\beta$-phase was also observed in cast AZ31 Mg alloy during FSP [11]. Generally, it takes dozens of hours to achieve the complete solid solution of $\beta$-phase by traditional solid solution treatment, while FSP only takes tens of seconds. This phenomenon can be due to two main factors. On the one hand, FSP promotes grain refinement and shortens the diffusion distance of elements. On the other hand, the severe plastic deformation during FSP makes the diffusion mechanism of elements change from bulk diffusion to tube diffusion, increasing the diffusion rate by three orders of magnitude [13]. Because of the obvious shortening of diffusion distance and the increasing of diffusion rate, the secondary phases in $\mathrm{Mg}$ alloys are completely dissolved instantly during FSP. Usually, this phenomenon exists in the FSP of precipitationstrengthened $\mathrm{Mg}$ alloys, including $\mathrm{AZ}$ series [11, 14, 15], ZK series [16], and rare-earth Mg alloys [17-21].

The rapid dissolution of secondary phases during FSP improves the hot workability but leads to the decrease in the strength of the Mg alloys. Therefore, Feng and $\mathrm{Ma}$ [9] firstly adopted FSP and aging duplex process to improve the comprehensive mechanical properties of AZ91 Mg alloy. Subsequently, Xiao et al. [17] and Afrinaldi et al. [22] indicated that FSP combined with aging was an effective approach to improve the mechanical properties of $\mathrm{Mg}-\mathrm{Gd}-\mathrm{Y}-\mathrm{Zr}$ and $\mathrm{AMX} 602 \mathrm{Mg}$ alloys, respectively. Similarly, Jin et al. [23] also conducted a post-aging heat treatment after FSP. Figure 1 shows the microstructures of the as-cast base material (BM), FSP, and aged samples of AE42 Mg alloy. Through the duplex process of FSP and post-aging treatment, gth, ultimate tensile strength, and elongation of the cast AE42 Mg alloy along transverse direction (TD) and processing direction (PD) are increased by $84 \%, 56 \%$, and $133.6 \%$, respectively (Fig. 2). It should be noted that the structural factors affecting the strength of FSPed AE42 Mg alloy are ranked as the sethe yield strencondary phase, grain orientation, and grain size. These experimental outcomes indicated that the duplex process combining FSP and post-aging treatment is an effective method to control the comprehensive mechanical properties of the precipitation-strengthened $\mathrm{Mg}$ alloys. 

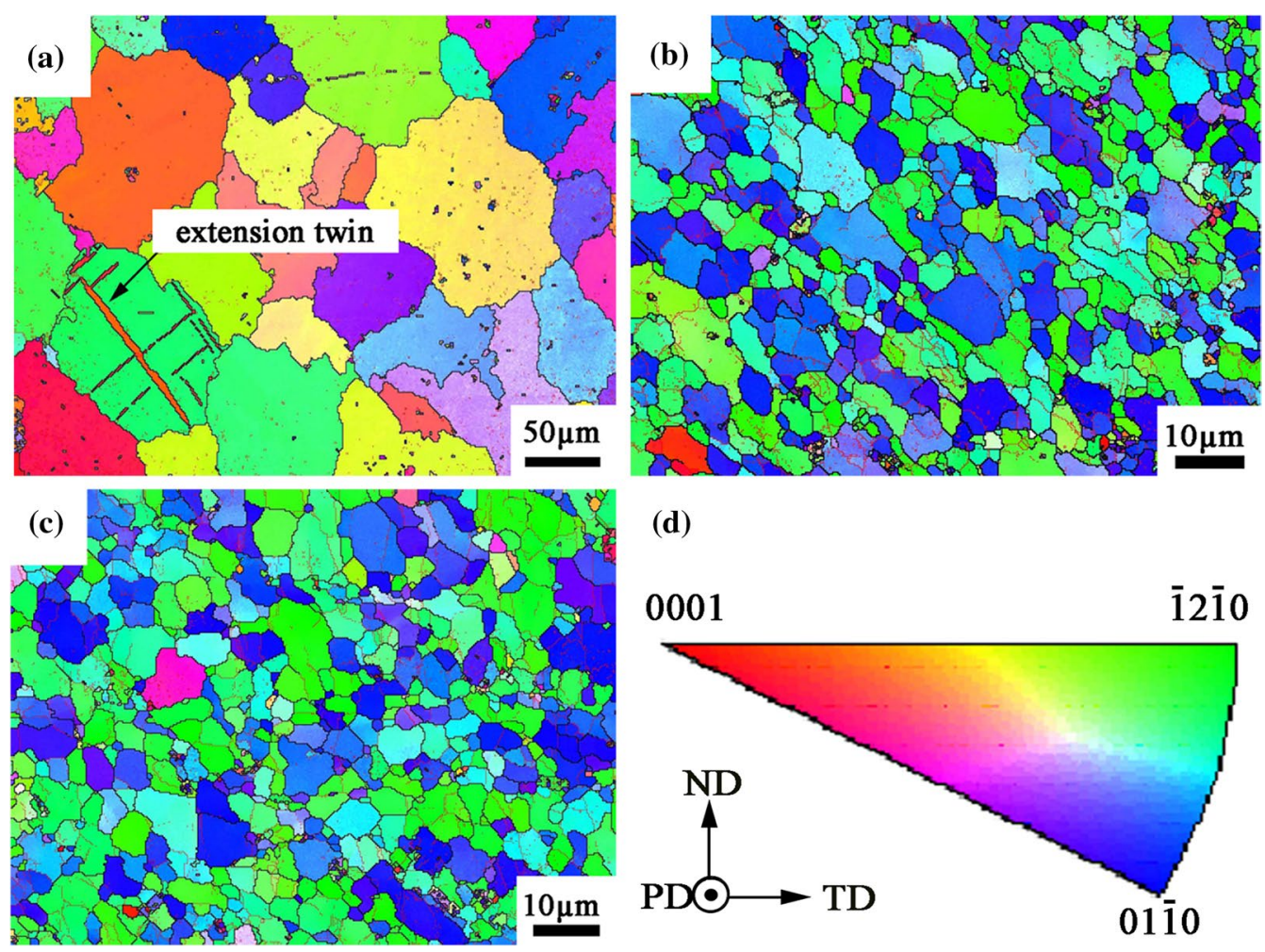

(d)

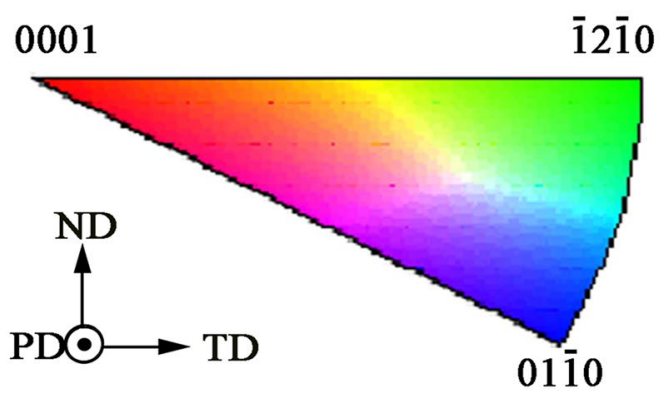

Fig. 1 Microstructures of a BM, b FSPed, $\mathbf{c}$ aged samples, $\mathbf{d}$ legend and direction [23]. ND normal direction, $P D$ processing direction, $T D$ transverse direction

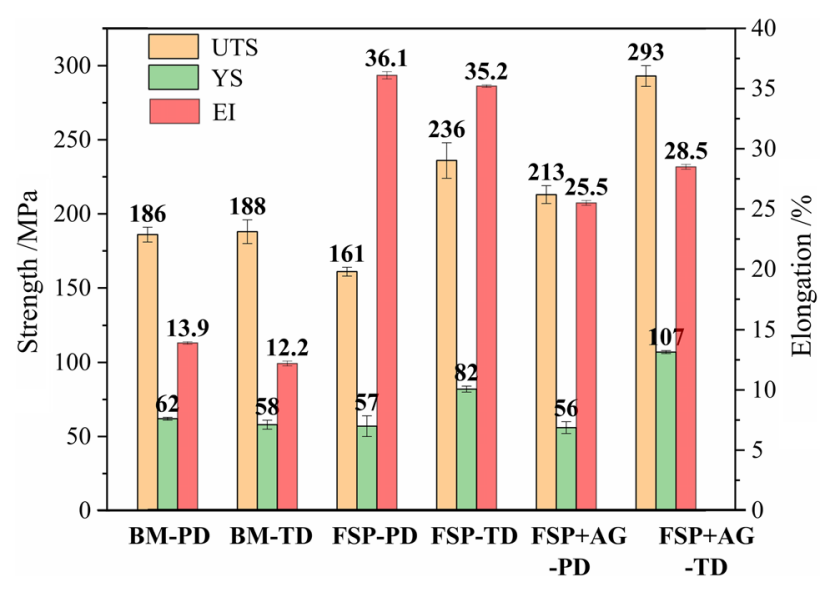

Fig. 2 Tensile properties of the BM, FSPed, and aged samples tested along TD and PD directions, respectively [23]

In recent years, FSP has also become an effective method for repairing fusion-welded joints of $\mathrm{Mg}$ alloys. $\mathrm{Xu}$ and $\mathrm{Bao}$ [24] used rapid cooling FSP to repair the tungsten inert gaswelded joint of AZ31 Mg alloy. The results showed that FSP promoted the solid solution of the coarse eutectic $\beta$-phase; furthermore, the grain size was refined to $3.1 \mu \mathrm{m}$, and the modified joint had excellent strength and plasticity. Kumar et al. [25] reported that the strength and plasticity of laserwelded joints of WE43 rare-earth Mg alloy were improved by FSP. Karthik et al. [26] demonstrated out that FSP could be used as a pretreatment process before the fusion welding of $\mathrm{Mg}$ alloys to effectively prevent the formation of liquefaction cracks in the heat-affected zone (HAZ). The above studies confirm that FSP is an effective method to repair fusion-welded joints of $\mathrm{Mg}$ alloys.

\subsection{Preparation of Fine-, Ultrafine-, and Nano-grained Mg Alloys}

FSP can be used to prepare fine-, ultrafine-, and nanograined $\mathrm{Mg}$ alloys. According to the microstructural characteristics, processing zones of FSPed Mg alloys are usually divided into the stir zone (SZ), thermomechanically affected zone (TMAZ), and HAZ. The SZ is subjected to the mechanical stirring of the shoulder and the pin during FSP at high temperature, resulting in the occurrence of dynamic recrystallization and formation of equiaxed recrystallized grains. By comparison, the mechanical action and heat input in the TMAZ are considerably reduced. Thus, only partial recrystallization occurs and the grain shows the deformation characteristics of elongation. The grain coarsening of the HAZ occurs only at high temperature. 
Because of the remarkable grain refinement effect in the SZ, researchers mainly focus on the mechanism of grain refinement in the SZ and optimize the FSP process parameters (such as the shape and size of the stir tool, rotational speed, travel speed, cooling medium, and processing pass) to obtain fine-, ultrafine-, and even nano-grained $\mathrm{Mg}$ alloys. Grain refinement is mainly due to the dynamic recrystallization of $\mathrm{Mg}$ alloys during FSP; the recrystallization mechanism includes continuous dynamic recrystallization, discontinuous dynamic recrystallization, and twinning-induced recrystallization [27, 28]. The recrystallization mechanism is mainly related to the degree of deformation, deformation rate, and temperature [29]. However, there is no unified conclusion about the recrystallization mechanism during FSP. Feng and Ma [27] claimed that the discontinuous dynamic recrystallization and twinning-induced recrystallization occurred in the FSPed AZ80 Mg alloy. Chai et al. [30] inferred that the continuous dynamic recrystallization occurred in FSPed AZ31 Mg alloys. Similar results had been concluded for FSPed AE42 Mg alloy [23]. However, Chai et al. [31] concluded that both continuous and discontinuous dynamic recrystallization occurred during FSPed AZ91 Mg alloys.

The grain size of $\mathrm{Mg}$ alloys obtained by conventional FSP is $1-10 \mu \mathrm{m}[30,32-41]$. To obtain ultrafine- or nano-grained Mg alloys, Chang et al. [6] used the copper mold with liquid nitrogen as a gasket to reduce the processing temperature and increase the cooling rate, finally obtaining ultrafine grains (100-300 nm). Similarly, Du and Wu [35] obtained the ultrafine-grained $(300 \mathrm{~nm}) \mathrm{Mg}$ alloy by a similar rapid heat sink method. Subsequently, Chang et al. [42] obtained nano-grains ( $85 \mathrm{~nm}$ ) by two-pass repetitive FSP when using a rapid heat sink.

Although lowering the processing temperature is beneficial to refine the grains, low temperature reduces the molding quality, and the defects such as tunnel holes may appear in the processing zone. In order to ensure that the fine-grained $\mathrm{Mg}$ alloys prepared by FSP have good formability, Del Valle et al. [43] used two-pass FSP to prepare ultrafine-grained Mg alloys. In their study, a gasket insulation device was used to increase the heat input and improve formability during first-pass FSP, while a liquid nitrogen cooling device was used to reduce the heat input to prevent the growth of recrystallized grains during the second pass. The ultrafine-grained $\mathrm{Mg}$ alloys prepared by this method had a better surface with the grain size being decreased to $400 \mathrm{~nm}$.

In order to reduce the cost of liquid nitrogen cooling, while pursuing the degree of grain refinement, the submerged friction stir processing (SFSP) was proposed. Darras and Kishta [39], Chai et al. [31], and Huang et al. [44] employed SFSP to obtain fine-grained AZ31, AZ91, and AZ80 Mg alloys, respectively.
In Mg alloys with an HCP structure, the base slip has a lower critical resolved shear stress than the prismatic and pyramidal slips; therefore, it is easy to process them during FSP, leading to obvious basal texture in the processed zone. In addition, different processing zones are subjected to different mechanical effects of the stir tool, further leading to different characteristics of basal texture. Woo et al. [45] characterized the texture of each region of the FSPed AZ31 $\mathrm{Mg}$ alloy. The original rolling texture was retained in the BM with the $c$-axis of the transition zone between the SZ and the BM being parallel to the TD. Meanwhile, the basal plane in the SZ was cylindrically distributed around the surface of the pin, which indicated that the SZ was mainly controlled by basal slip, showing a simple shear deformation mode.

The inhomogeneity of metal flow along the thickness direction during FSP leads to the different distribution of texture in the direction of thickness. Yuan et al. [46] investigated the texture distribution in the SZ of the FSPed AZ31 $\mathrm{Mg}$ alloy along the thickness direction. At $0.5 \mathrm{~mm}$ from the upper surface, the angle between the $c$-axis and the PD was about $45^{\circ}$. With the increase in thickness, the angle decreased gradually. At $1.5 \mathrm{~mm}$ from the upper surface, the $c$-axis was parallel to the PD, indicating that the shear deformation was mainly affected by the shoulder action in the region near the upper surface, whereas the effect of the pin on the shear deformation was enhanced as the thickness was increased. It is worth mentioning that there are many factors affecting the texture distribution in the processed zone, such as the shape and size of stir tool, rotation speed, travel speed, reduction, and thickness of the plate. Therefore, the texture characteristics of the FSP samples obtained according to different processing parameters can be rather different. Yu et al. [47] found that Zener-Hollomon parameters (Z) also influenced the texture of the SZ. Indeed, by increasing the values of the $\mathrm{Z}$ parameters, the ND of the basal plane deflected from the PD to the vertical direction. Moreover, Jin et al. [23] reported that the post-aging heat treatment after FSP could also impact the orientation of grains for the AE42 rare-earth $\mathrm{Mg}$ alloy.

The grain orientation significantly weakens the finegrained strengthening effect of FSPed Mg alloys. The linear relationship between yield strength and grain size is characterized by the Hall-Petch (H-P) equation as follows:

$\sigma_{\mathrm{s}}=\sigma_{0}+k d^{-1 / 2}$,

where $\sigma_{\mathrm{s}}$ is the yield strength, $\sigma_{0}$ is the friction stress, $k$ is the stress concentration factor, and $d$ is the average grain size. Friction stress and stress concentration factor reflect the degree of grain refinement. The $k$ of coarse-grained

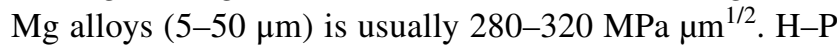
parameters of AZ31 Mg alloy prepared by different processes are reported in Table 1. Compared with rolling, 
Table 1 H-P parameters for AZ31 Mg alloy [51]

\begin{tabular}{|c|c|c|c|c|c|}
\hline Preparation process & Loading direction & Grain size $(\mu \mathrm{m})$ & $\sigma_{0}(\mathrm{MPa})$ & $k\left(\mathrm{MPa} \cdot \mu \mathrm{m}^{1 / 2}\right)$ & References \\
\hline Rolling & Tensile//rolling direction & $5.2-24$ & 85 & 200 & {$[52]$} \\
\hline Rolling & Tensile//rolling direction & $5.2-21.5$ & 131 & 250 & {$[53]$} \\
\hline Rolling & Tensile//rolling direction & $5-17.3$ & 89 & 231 & {$[53]$} \\
\hline Rolling & Tensile//transverse direction & $13-140$ & 115 & 272 & {$[54]$} \\
\hline Rolling & Tensile//rolling direction & $13-140$ & 88 & 281 & {$[54]$} \\
\hline Rolling & Tensile//normal direction & $26-78$ & 12.2 & 228 & {$[51]$} \\
\hline Rolling & Tensile $\angle$ normal direction $=22.5^{\circ}$ & $26-78$ & 10.5 & 231 & {$[51]$} \\
\hline Rolling & Tensile $\angle$ normal direction $=45.0^{\circ}$ & $26-78$ & 18.2 & 158 & {$[51]$} \\
\hline Rolling & Tensile $\angle$ normal direction $=67.5^{\circ}$ & $26-78$ & 26.5 & 221 & {$[51]$} \\
\hline Rolling & Tensile//transverse direction & $26-78$ & 41.1 & 411 & {$[51]$} \\
\hline Extrusion & Tensile//extrusion direction & $2.5-8.0$ & 80 & 304 & [48] \\
\hline Extrusion & Compressive//extrusion direction & $3-11$ & 22 & 390 & {$[55]$} \\
\hline ECAP & Tensile//extrusion direction & $5-32$ & 30 & 170 & {$[56]$} \\
\hline ECAP & - & - & 30 & 170 & {$[57]$} \\
\hline ECAP & Tensile//extrusion direction & $2.2-8$ & 30 & 180 & {$[58]$} \\
\hline ECAP & Tensile//extrusion direction & $2.5-48.3$ & 85.2 & 205 & [59] \\
\hline ECAP & Tensile//extrusion direction & $2-55$ & 122 & 207 & {$[60]$} \\
\hline ECAP & Tensile//extrusion direction & $9-22$ & 10 & 327 & {$[61]$} \\
\hline ECAP + extrusion & Tensile//extrusion direction & $6-22$ & 50 & 343 & {$[61]$} \\
\hline Electron beam welding & Tensile//welding direction & $11-38$ & 62 & 202 & {$[62]$} \\
\hline FSP & Tensile//forward direction & $2.6-6.1$ & 10 & 160 & {$[48]$} \\
\hline
\end{tabular}

extrusion, equal-channel angular pressing (ECAP), and electron beam welding, the $k$ of fine-grained FSPed Mg alloys is relatively low. Wang et al. [48] showed that the FSPed AZ31 $\mathrm{Mg}$ alloy had lower fine-grained strengthening sensitivity than the extruded AZ31 Mg alloy. Yuan et al. [49] demonstrated that the H-P equation of FSPed AZ31 Mg alloy was $\sigma_{\mathrm{s}}=24+119 d^{-1 / 2}$, which showed that that alloy had a low $k$ [50]. This was mainly due to the soft orientation of Mg alloys caused by FSP. The soft orientation decreases the strength of fine-grained FSPed Mg alloys.

In general, FSP can refine the grains of $\mathrm{Mg}$ alloys and improve their strength and plasticity. Furthermore, it has been shown that FSP can promote the grain refinement of $\mathrm{Mg}$ alloys as well. However, the total elongation and uniform elongation are still low. For examples, Xin et al. [63] showed that the elongation of AZ31 Mg alloy has reduced by $41 \%$ after FSP, as the grain size reduced from 26 to $12 \mu \mathrm{m}$. Zheng et al. [64] also found that the same phenomenon occurred on the FSPed NZ20 K Mg alloy. The grain size was reduced from 20 to $4 \mu \mathrm{m}$, while the elongation decreased from 13 to $11 \%$. The main reason is that the ability to store dislocations in fine grains is weak during plastic deformation, which results in the lack of strain hardening ability, thus causing the plastic instability and low elongation [64].

At present, additional studies have been carried out on the effect of FSP on the strength of Mg alloys, and the several strength models also have been established. However, there is limited knowledge of the quantitative effect of FSP on the elongation of $\mathrm{Mg}$ alloys. Indeed, the present authors found that the ratio of initial work-hardening rate $\left(\theta_{0}\right)$ to saturation stress $\left(\sigma_{\mathrm{s}}\right)$ of fine-grained FSPed AZ31 Mg alloy is in agreement with the exponential function relationship with uniform elongation (Fig. 3). Furthermore, we observed that the high uniform elongation of FSPed AZ31 Mg alloy can be obtained by increasing the value of $\sigma_{\mathrm{s}}$ and/or decreasing the value of $\theta_{0}$. The quantitative relationship between work-hardening properties and uniform elongation of FSPed

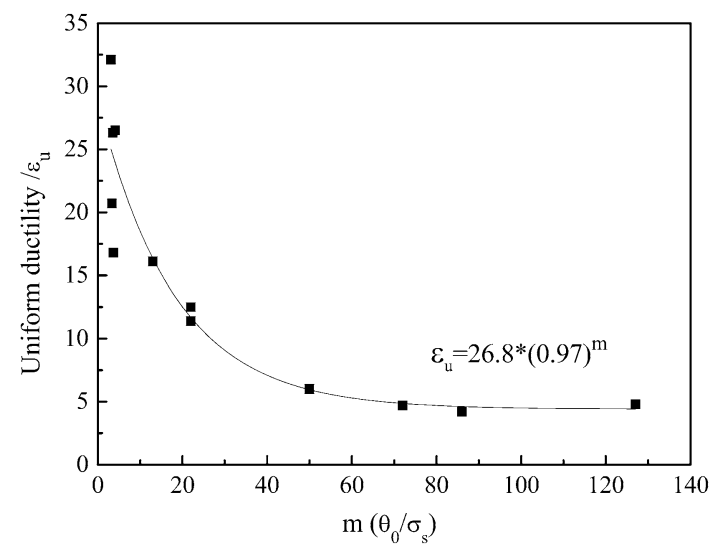

Fig. 3 Variation in the uniform elongation as a function of the ratio of $\theta_{0}$ to $\sigma_{\mathrm{s}}$ 
AZ31 Mg alloy has been established and provides an effective method for describing the uniform elongation of the FSPed AZ31 Mg alloy.

A practical method for improving the strength and plasticity of $\mathrm{Mg}$ alloys simultaneously is to construct a bimodal grain structure in the Mg alloys. Zhang et al. [65] prepared the bimodal grain structure in $\mathrm{Mg}$ alloys using hard-paterolling. It can be concluded that ultrafine- and nano-grained structures contribute to high strength, whereas coarse grains facilitate good plasticity. Raja et al. [66] used FSP to obtain the bimodal grain structure in the cast AZ91 Mg alloy and reported that the elongation of bimodal grain structure was related to the proportion and distribution of fine grains. Although the above research did not describe how to improve the strength and plasticity simultaneously in the bimodal grain structure of FSPed Mg alloys, it promoted the use of FSP to construct a bimodal grain structure.

FSP not only causes grain refinement and texture transformation, but also induces deformation twins, thus improving the strength and plasticity of fine-grained Mg alloys. Yuan and Mishra [67] indicated that the twins promoted the elongation of FSPed AZ31 Mg alloy. Similarly, Shang et al. [68] employed FSP to induce the deformation twins in AZ31 Mg alloy, improving its strength significantly. In addition, $\mathrm{Xu}$ et al. [69] obtained a large number of $\{101 \overline{2}\}$ twins in the FSPed AZ31 Mg alloy. They showed that twinning promoted grain refinement, thus increasing the yield strength of FSPed AZ31 Mg alloys. Moreover, $\{101 \overline{2}\}$ twins provided enough space for dislocation motion. As dislocation moved to the twin boundaries, the perfect dislocation decomposed into half dislocations, which resulted in dislocation accumulation and improved the strain hardening rate to increase the uniform elongation of FSPed AZ31 Mg alloy.

\subsection{Superplastic Deformation Behavior}

The microstructure of Mg alloys prepared by FSP is refined and homogenized with low dislocation density and a high proportion of high-angle grain boundaries, which are beneficial to the superplastic deformation. The different superplastic deformation behaviors (microcrystalline structure superplasticity, high strain rate superplasticity (HSRS), and low-temperature superplasticity (LTSP)) of FSPed Mg alloys are here described.

\section{(1) Superplasticity of microcrystalline structure}

The superplasticity of the microcrystalline structure requires the material having fine equiaxed grains with the average grain size lower than $10 \mu \mathrm{m}$ and good thermal stability. Most microcrystalline superplastic Mg alloys are two-phase or multiphase alloys. The secondary phase can improve the microstructure stability and prevent grain coarsening. The deformation conditions of microcrystalline superplasticity are high deformation temperature $\left(T>0.5 T_{\mathrm{m}}, T_{\mathrm{m}}\right.$ is the melting point of metal) and a relatively low strain rate $\left(10^{-4}-10^{-1} \mathrm{~s}^{-1}\right)$.

The superplastic behavior of FSPed ZK60 and ZK60-Y $\mathrm{Mg}$ alloys was presented by Ma et al. [70]. FSP promoted the rapid dissolution of the $\mathrm{MgZn}$ phase in ZK60 Mg alloy. When the temperature was $275^{\circ} \mathrm{C}$, the elongation of FSPed ZK60 sample was as high as $940 \%$; as the temperature increased, the pinning effect of the secondary phase on $\mathrm{Mg}$ matrix weakened, while the grains coarsened and the superplasticity decreased significantly. In contrast, $\mathrm{W}-\mathrm{Mg}_{3} \mathrm{Zn}_{3} \mathrm{Y}_{2}$ in ZK60-Y alloy had a good pinning effect on the Mg matrix, which remarkably improved the thermal stability of the FSP fine-grained structure. Therefore, FSPed ZK60-Y alloy still exhibits superplasticity at $400-450{ }^{\circ} \mathrm{C}$. Xie et al. [71] also confirmed that the $\mathrm{W}$ phase was conducive to the superplastic stability of FSPed Mg-6.19Zn-1.1Y-0.46Zr alloy. The superplastic deformation behavior of FSPed AZ80 Mg alloy was systematically investigated by Takayama et al. [72]. The elongation of FSPed sample was 10-30 times higher than that of the $\mathrm{BM}$ at $300{ }^{\circ} \mathrm{C}$ and low strain rate. Zhang et al. [73] performed FSP on hot-rolled AZ31 Mg alloy plates, resulting in the grain size being refined from 92 to $11.4 \mu \mathrm{m}$. At $450{ }^{\circ} \mathrm{C}$ and the strain rate of $5 \times 10^{-4} \mathrm{~s}^{-1}$, the elongation of FSPed alloy reached $1050 \%$. The HSRS of $268 \%$ was produced at the strain rate of $1 \times 10^{-2} \mathrm{~s}^{-1}$.

\section{(2) High strain rate superplasticity}

In order to improve the efficiency of superplastic deformation, the high strain rate superplastic deformation behavior of $\mathrm{Mg}$ alloys was investigated. HSRS indicated the superplasticity of materials with an elongation greater than $200 \%$ when the strain rate exceeds $1 \times 10^{-2} \mathrm{~s}^{-1}$ [74]. In general, grain refinement and high proportion of high-angle grain boundaries are beneficial to HSRS.

Chai et al. [75] carried out FSP on cast AZ91 Mg alloy in air and water and compared their superplastic deformation behavior, showing that the average grain sizes of FSPed samples in air and water were $7.8 \mu \mathrm{m}$ and $1.2 \mu \mathrm{m}$, respectively. Submerged FSPed sample exhibited higher superplasticity than those in air. When the superplastic deformation was conducted at $350{ }^{\circ} \mathrm{C}$ and $2 \times 10^{-2} \mathrm{~s}^{-1}$, the submerged FSPed samples exhibited HSRS with the elongation of $990 \%$, while the elongation of the FSPed sample in air was only $158 \%$. It is generally accepted that grain boundary slip (GBS) is the main mechanism of superplastic deformation. Yang et al. [76] showed that the grain size of hot-rolled $\mathrm{Mg}-\mathrm{Zn}-\mathrm{Y}-\mathrm{Zr}$ alloy was refined to $4.5 \mu \mathrm{m}$ after FSP as the W phases were uniformly distributed on the $\mathrm{Mg}$ matrix. The proportion 
of high-angle grain boundaries reached $91 \%$, whereas the elongation of FSPed sample was $1110 \%$ at $450{ }^{\circ} \mathrm{C}$ and $1 \times 10^{-2} \mathrm{~s}^{-1}$. It was also found that the thermal stability of the fine-grained structure and high-angle grain boundaries plays a major role in HSRS. Mohan et al. [77] performed FSP on as-rolled AZ31 and cast AZ91 Mg alloys, whose grain size was refined to $0.8 \mu \mathrm{m}$ and $0.5 \mu \mathrm{m}$, respectively. At $330{ }^{\circ} \mathrm{C}$ and $1 \times 10^{-2} \mathrm{~s}^{-1}$, the elongation of FSPed AZ91 sample was $1251 \%$. Due to the relatively low content of alloying elements, the high-temperature microstructure stability of FSPed AZ31 alloy was poor, showing only superplasticity and not HSRS.

(3) Low-temperature superplasticity (LTSP)

LTSP indicates the superplasticity of materials below $0.5 T_{\mathrm{m}}$. Zhang et al. [78] confirmed that the AZ91 Mg alloy prepared by FSP exhibited LTSP; after FSP, the grain size of cast
AZ91 Mg alloy was refined to $\sim 3 \mu \mathrm{m}$, while the $\beta$-particles were broken and uniformly distributed on the $\mathrm{Mg}$ matrix. The high elongation of $1604 \%$ was obtained at $300^{\circ} \mathrm{C}$ and $1 \times 10^{-4} \mathrm{~s}^{-1}$. However, when the temperature was decreased to $200{ }^{\circ} \mathrm{C}$ and the strain rate was $3 \times 10^{-3} \mathrm{~s}^{-1}$, the elongation dramatically decreased to $204.4 \%$, showing LTSP. Previous studies reported that LTSP also existed in FSPed ZK60 [70, 79] and AM60B [80] Mg alloys.

The superplasticity parameters of FSPed Mg alloys are summarized in Table 2. The brands of $\mathrm{Mg}$ alloys mainly include AZ31, AZ91, ZK60, and rare-earth Mg alloys. The superplastic deformation behavior of FSPed Mg alloys has the following characteristics. Firstly, the grain refinement induced by FSP is beneficial to the superplasticity of $\mathrm{Mg}$ alloys, especially for HSRS and LTSP. It is generally accepted that superplasticity can be obtained only when the grain size is less than $10 \mu \mathrm{m}$, but it was demonstrated that the superplasticity, even HSRS, can still be obtained when the grain size was larger than $10 \mu \mathrm{m}$ for FSPed AZ31 Mg alloy

Table 2 Superplasticity parameters of FSPed Mg alloys

\begin{tabular}{|c|c|c|c|c|c|c|c|}
\hline Alloys & State & Grain size $(\mu \mathrm{m})$ & $\begin{array}{l}\text { Tempera- } \\
\text { ture }\left({ }^{\circ} \mathrm{C}\right)\end{array}$ & Strain rate $\left(\mathrm{s}^{-1}\right)$ & Elongation (\%) & Behavior & References \\
\hline AZ31 & Rolled & 11.4 & 450 & $5 \times 10^{-4}$ & 1050 & & [73] \\
\hline AZ31 & Rolled & 11.4 & 450 & $1 \times 10^{-2}$ & 268 & HSRS & [73] \\
\hline AZ31 & Rolled & $0.94-3.21$ & 450 & $5 \times 10^{-4}$ & 405 & & {$[83]$} \\
\hline AZ61 & $\mathrm{SiO}_{2}$ & 0.8 & 400 & $3 \times 10^{-1}$ & 454 & HSRS & [84] \\
\hline AZ61 & & $7-8$ & 300 & $1 \times 10^{-4}$ & 235 & & {$[85]$} \\
\hline AZ80 & Cast & - & 300 & $1.4 \times 10^{-4}$ & 541 & & [72] \\
\hline AZ91 & Cast & 4 & 300 & $5 \times 10^{-4}$ & 1050 & LTSP & [86] \\
\hline AZ91 & Cast & $\sim 3$ & 300 & $1 \times 10^{-4}$ & 1604 & LTSP & [78] \\
\hline AZ91 & Cast & $\sim 3$ & 350 & $2 \times 10^{-2}$ & 207 & HSRS & [78] \\
\hline AZ91 & Cast & 7.9 & 325 & $1 \times 10^{-4}$ & 311 & & [81] \\
\hline AZ91 & Cast & 0.5 & 330 & $1 \times 10^{-2}$ & 1251 & HSRS & [77] \\
\hline AZ91 & Cast & 0.5 & 330 & $3 \times 10^{-2}$ & 827 & HSRS & [77] \\
\hline AZ91 & Cast & 1.2 & 350 & $2 \times 10^{-2}$ & 990 & HSRS & [87] \\
\hline ZK60 & & $2-5$ & 275 & $3 \times 10^{-4}$ & 940 & LTSP & [70] \\
\hline ZK60 & Extrusion & 2.9 & 300 & $3 \times 10^{-4}$ & 1390 & LTSP & [79] \\
\hline AM60B & Cast & 2.5 & 200 & $1 \times 10^{-4}$ & $\sim 550$ & LTSP & [80] \\
\hline AM60B & Cast & 2.5 & 300 & $1 \times 10^{-4}$ & $\sim 1280$ & LTSP & [82] \\
\hline MB8 & Rolled & 6 & 400 & $4 \times 10^{-4}$ & 231.2 & & {$[88]$} \\
\hline $\mathrm{Mg}-6.19 \mathrm{Zn}-1.1 \mathrm{Y}-0.46 \mathrm{Zr}$ & Extrusion & 5.2 & 450 & $3 \times 10^{-3}$ & 635 & & [71] \\
\hline $\mathrm{Mg}-6.19 \mathrm{Zn}-1.1 \mathrm{Y}-0.46 \mathrm{Zr}$ & Extrusion & 5.2 & 450 & $1 \times 10^{-2}$ & 225 & HSRS & [71] \\
\hline $\mathrm{Mg}-7.12 \mathrm{Zn}-1.2 \mathrm{Y}-0.84 \mathrm{Zr}$ & Rolled & 4.5 & 450 & $1 \times 10^{-2}$ & 1110 & HSRS & [76] \\
\hline $\mathrm{Mg}-7 \mathrm{Zn}-1.2 \mathrm{Y}-0.8 \mathrm{Zr}$ & & 4.6 & 450 & $1 \times 10^{-2}$ & 1200 & & [89] \\
\hline $\mathrm{Mg}-10 \mathrm{Gd}-3 \mathrm{Y}-0.5 \mathrm{Zr}$ & Cast & 6.1 & 415 & $1 \times 10^{-3}$ & 1110 & & {$[90]$} \\
\hline $\mathrm{Mg}-1.2 \mathrm{Zn}-1.7 \mathrm{Y}-0.53 \mathrm{Al}-0.27 \mathrm{Mn}$ & Rolled & 2.8 & 350 & $1 \times 10^{-4}$ & 335 & & {$[82]$} \\
\hline $\mathrm{Mg}-3.99 \mathrm{Y}-3.81 \mathrm{Nd}-0.53 \mathrm{Zr}$ & Cast & $\sim 2$ & 475 & $2 \times 10^{-2}$ & 631 & HSRS & [91] \\
\hline $\mathrm{Mg}-4.27 \mathrm{Y}-2.94 \mathrm{Nd}-0.51 \mathrm{Zr}$ & Cast & 1.3 & 485 & $1 \times 10^{-1}$ & 549 & HSRS & [92] \\
\hline $\mathrm{Mg}-2.08 \mathrm{Ag}-2.07 \mathrm{Nd}-0.6 \mathrm{Zr}$ & Cast & 0.63 & 450 & $1 \times 10^{-2}$ & 1630 & HSRS & [93] \\
\hline $\mathrm{Mg}-2.08 \mathrm{Ag}-2.07 \mathrm{Nd}-0.6 \mathrm{Zr}$ & Cast & 0.63 & 350 & $3 \times 10^{-3}$ & 850 & LTSP & [93] \\
\hline
\end{tabular}


[73]. Secondly, the secondary phase has a significant effect on the superplasticity of FSPed Mg alloys. In order to obtain excellent superplasticity, it is necessary to increase the thermal stability of $\mathrm{Mg}$ alloys by improving the high-temperature pinning effect of the secondary phase on grain boundaries. The effect of alloy composition on superplasticity is mainly reflected in the action of the secondary phase on the thermal stability of the microstructure. The superplasticity of FSPed Mg alloys with different compositions was investigated by Jain et al. [81, 82]; their results showed that FSPed AZ91C alloy had a large number of secondary phases such as $\mathrm{Mg}_{17}(\mathrm{Al}, \mathrm{Zn})_{12}, \mathrm{Mg}_{2} \mathrm{Si}$, and $\mathrm{Al}_{8} \mathrm{Mn}_{5}$, which significantly improved the thermal stability of the alloy. Furthermore, the FSPed sample of $\mathrm{Mg}-1.2 \mathrm{Zn}-1.7 \mathrm{Y}-0.53 \mathrm{Al}-0.27 \mathrm{Mn}$ alloy also had a large number of second phases such as $\mathrm{W}$ and $\mathrm{C}_{15}$. As a result, the FSPed sample exhibited excellent thermal stability at high temperature. Therefore, the superplasticity of FSPed sample of $\mathrm{Mg}-1.2 \mathrm{Zn}-1.7 \mathrm{Y}-0.53 \mathrm{Al}-0.27 \mathrm{Mn}$ alloy was higher than that of FSPed AZ31, Mg-10.6Zn-2.3Y and $\mathrm{Mg}-4.3 \mathrm{Zn}-0.7 \mathrm{Y} \mathrm{Mg}$ alloys. Thirdly, a high proportion of high-angle grain boundaries are conducive to superplastic deformation.

Generally, texture also plays an important role in the deformation behavior of $\mathrm{Mg}$ alloys at room temperature; however, its effect on superplastic deformation behavior remains controversial. Kaibyshev et al. [94] reported that the flow stress and superplastic elongation of $\mathrm{Mg}$ alloys were anisotropic due to texture. Similarly, Lin et al. [95] proved that texture improved the LTSP of fine-grained $\mathrm{Mg}$ alloy. In contrast, Del Valle and Ruano [96] and Panickeret et al. [97] indicated that the initial texture had little effect on the superplastic deformation of AZ31 Mg alloy. At present, there are only a few studies on the effect of texture on the superplastic deformation behavior of FSPed $\mathrm{Mg}$ alloys. Yang et al. [79] showed that although texture weakening occurred during superplastic deformation, the initial basal fiber texture still led to the anisotropy of superplastic deformation of FSPed ZK60 Mg alloy; this was mainly due to the different slip systems activated during superplastic deformation. The present authors studied the effect of texture on the superplastic deformation of FSPed AZ80 Mg alloy (Fig. 4). It can be seen that FSP resulted in the evident modification of texture with the $c$-axis tilting to the PD and TD with angles of $48^{\circ}-67^{\circ}$ and $75^{\circ}$, respectively (Fig. 4c). Moreover, $\langle 11 \overline{2} 0\rangle$ and $\langle\overline{1} 2 \overline{1} 0\rangle$ orientations were close to the TD (Fig. 4d). The average Schmid factor (SF) values of the FSPed samples for different slip systems are listed in Table 3. The results showed that the texture was beneficial to the activation of prismatic and pyramidal slips, which improved the superplasticity.

At present, there is no unified conclusion about the superplastic deformation mechanism of FSPed Mg alloy. It is generally believed that the superplastic deformation mechanism of FSPed Mg alloy is the multimechanism dominated by GBS [77, 84]. During the superplastic deformation of FSPed $\mathrm{Mg}$ alloy, the activation energy of GBS is slightly higher than that of grain boundary diffusion and lattice diffusion. GBS always causes stress concentration at the intersection of grain boundaries, which hinders GBS and produces pores. For example, Cao et al. [92] showed that stress concentration induced pores nucleation at the intersection of grain boundaries during superplastic deformation of FSPed $\mathrm{Mg}-\mathrm{Y}-\mathrm{Nd}$ alloy; it means that the GBS mechanism alone cannot ensure high superplasticity of FSPed Mg alloys. Therefore, it is necessary to have a coordinated deformation mechanism to promote stress relaxation and coordinate GBS. Previous studies showed that the coordinated deformation mechanisms for GBS were grain boundary diffusion [84], dislocation slip [98], and creep [72]. With regard to the superplastic failure mechanism of FSPed Mg alloy, it is generally believed that grain growth [75], followed by pore nucleation and growth [92] along the grain boundaries, can lead to fracture.

\subsection{Fabrication of Surface Mg Matrix Composites}

Surface metal matrix composites (SMMCs) are a class of promising structural materials due to their high hardness, good friction and wear resistance, and excellent corrosion resistance. In SMMCs, the matrix material is a metal, while the reinforcing phase consists of ceramic particles, whiskers, and fibers. At present, the Mg-based SMMCs reinforced by particles and fibers can be successfully prepared by FSP. As a result, the surface properties of SMMCs such as hardness, strength, and wear resistance are significantly increased.

In 2006, Morisada et al. [99] firstly used FSP to prepare Mg-based SMMCs. AZ31/MWCNTs (multiwalled carbon nanotubes) surface composites were successfully prepared by adding MWCNTs into AZ31 Mg matrix by machining grooves on the surface of the plate. This work triggered a research wave on the preparation of $\mathrm{Mg}$-based SMMCs by FSP. It is reported that FSP has many advantages in the fabrication of Mg-based SMMCs. For example, their low processing temperature can prevent the adverse interfacial reaction between reinforcing particles and Mg matrix. Furthermore, besides being environmentally friendly, the severe plastic deformation is beneficial to the fragmentation and uniform mixing of reinforcing particles.

One of the key factors for the preparation of Mg-based SMMCs by FSP is the addition of reinforcing particles. At present, there are three main ways to add reinforcing particles into the surface of $\mathrm{Mg}$ alloys: (1) machining grooves or drilling holes directly on the surface of the plates, and then filling the grooves or holes with reinforcing particles [100], as shown in Fig. 5a; (2) filling the reinforcing particles directly between two plates to create a sandwichlike structure, as shown in Fig. 5b; and (3) pre-assembling 


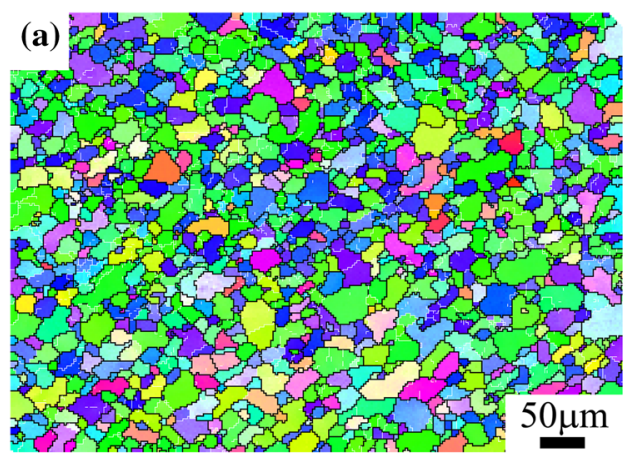

(c)
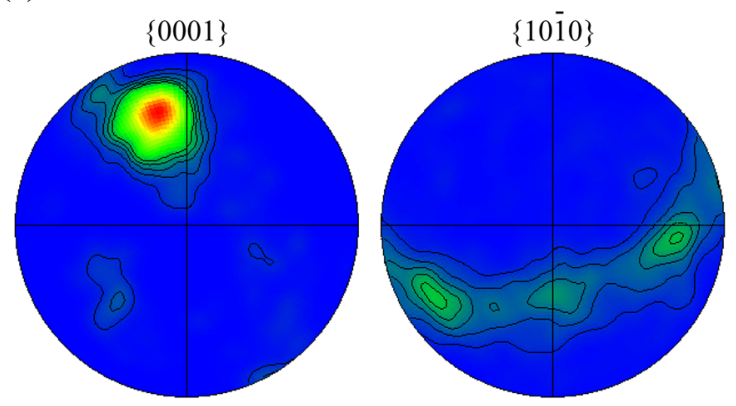

(d)

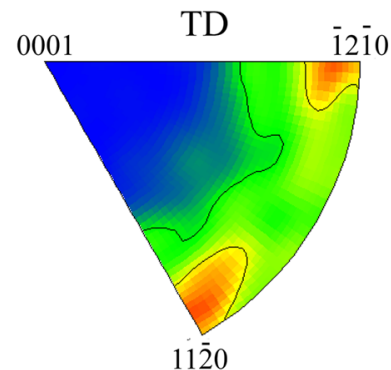

ND

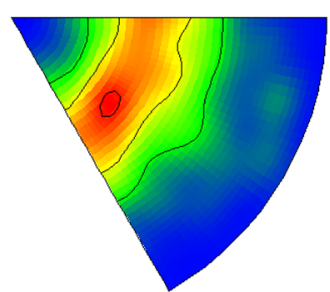

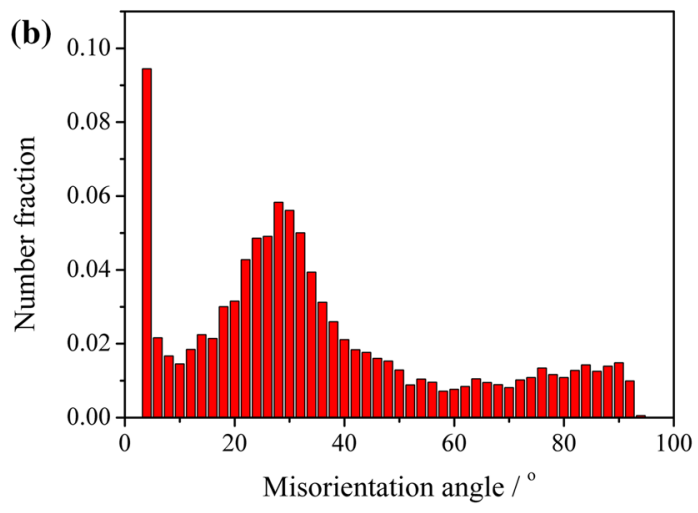

TD
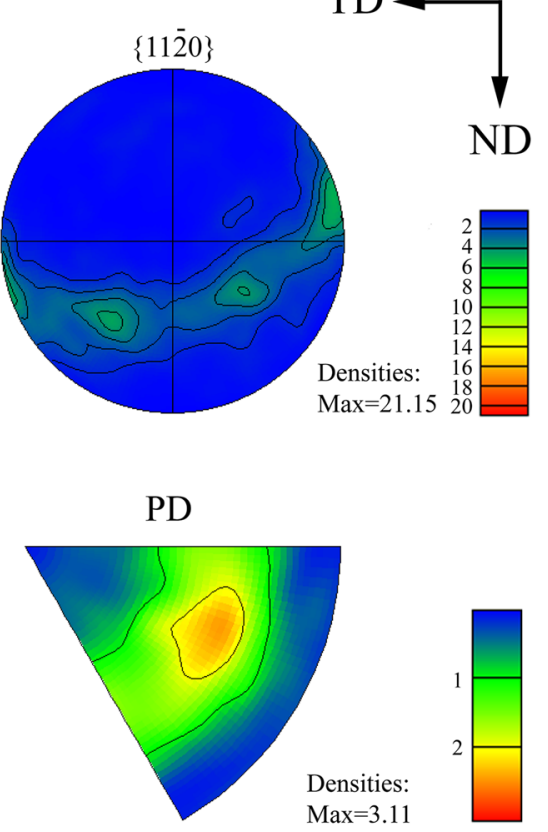

Fig. 4 Microstructure of FSPed AZ80 alloy: a EBSD map, $\mathbf{b}$ misorientation angle distribution, $\mathbf{c}$ pole figure, $\mathbf{d}$ inverse pole figure

Table 3 Average SF values of FSPed sample for different slip systems

\begin{tabular}{ll}
\hline Slip systems & SF \\
\hline Basal slip $\{0001\}\langle 11 \overline{2} 0\rangle$ & 0.252 \\
Prismatic slip $\{10 \overline{1} 0\}\langle 11 \overline{2} 0\rangle$ & 0.410 \\
Pyramidal $\langle a\rangle$ slip $\{10 \overline{1} 1\}\langle 11 \overline{2} 0\rangle$ & 0.425 \\
Pyramidal $\langle c+a\rangle$ slip $\{11 \overline{2} 1\}\langle 11 \overline{2} 3\rangle$ & 0.431 \\
Pyramidal $\langle c+a\rangle \operatorname{slip}\{11 \overline{2} 2\}\langle 11 \overline{2} 3\rangle$ & 0.376 \\
\hline
\end{tabular}

the reinforcing particles directly in a stir tool with a hollow structure for addition during FSP [101], as shown in Fig. 5c. In general, for the first method, in order to prevent the particles in the grooves and holes from flashing during FSP, a pinless tool is used to pretreat the area filled with particles firstly, and then a tool with a pin is used to process the $\mathrm{Mg}$ alloy plates. In the latter two methods, the tool with a pin is used directly during FSP.

The summary results of the study on preparing FSPed Mg-based SMMCs are shown in Table 4. At present, the brands of $\mathrm{Mg}$ alloys mainly include pure $\mathrm{Mg}$, AZ31, AZ61, AZ91, ZM21, ZK60, and RZ5. The reinforcing particles include carbon nanotubes (CNTs), carbon fiber, $\mathrm{SiC}, \mathrm{SiO}_{2}$, $\mathrm{Al}_{2} \mathrm{O}_{3}, \mathrm{~B}_{4} \mathrm{C}, \mathrm{TiC}, \mathrm{ZrO}_{2}$, fly ash, hydroxyapatite, and stainless steel powder. Many factors significantly influence the formability and mechanical properties of FSPed Mg-based SMMCs, such as the shape of the tool, rotational speed, rotation direction, traverse speed, processing depth, the size and type of reinforcing particles, number of the processing passes, and other processing parameters. The agglomeration and uniform distribution of reinforcing particles can be improved by increasing the processing passes. The surface hardness, tensile strength, and wear resistance of $\mathrm{Mg}$ 

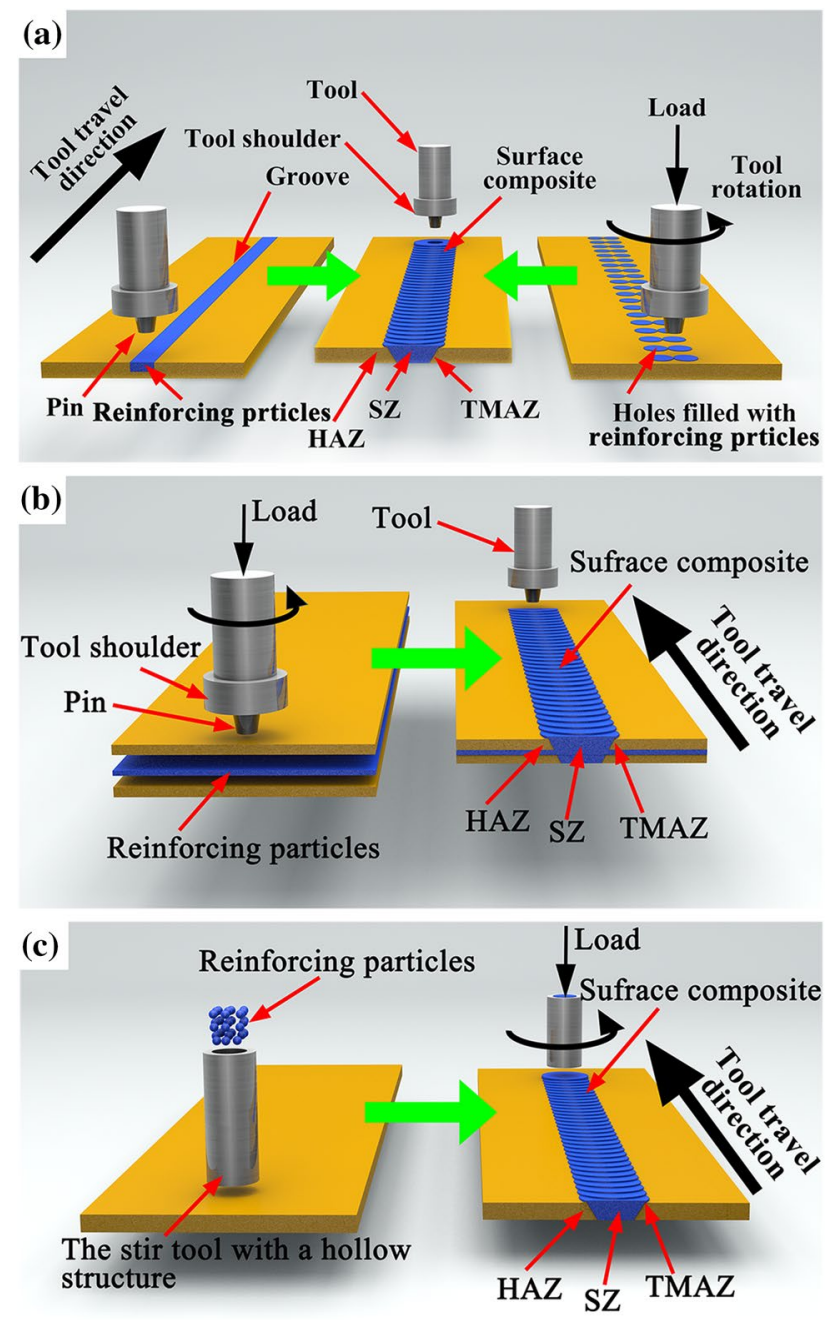

Fig. 5 Schematic representation of SMMCs fabrication by FSP

alloys are improved by adding reinforcing particles. Dispersion strengthening and fine-grained strengthening are the main mechanisms for improving of mechanical properties. Controlling the size and distribution of reinforcing particles plays a key role in the performance of Mg-based SMMCs.

Different reinforcing particles show obvious diversity in the reinforcing effect. For example, CNTs can effectively increase the elastic modulus, yield strength, and ultimate tensile strength of Mg-based SMMCs [102]. However, when CNTs are added to pure $\mathrm{Mg}$, they induce galvanic corrosion and decrease the corrosion resistance [103]. Similarly, the addition of $\mathrm{Mg}-18.8 \% \mathrm{Gd}-2 \% \mathrm{BN}$ can increase the strength and elongation of Mg-based SMMCs [104]. The addition of ceramic particles, such as $\mathrm{SiC}, \mathrm{SiO}_{2}, \mathrm{Al}_{2} \mathrm{O}_{3}, \mathrm{~B}_{4} \mathrm{C}, \mathrm{TiC}$, and $\mathrm{ZrO}_{2}$, improves wear resistance of $\mathrm{Mg}$-based SMMCs [101, 105-124]. It is interesting that among three types of particles of $\mathrm{SiC}, \mathrm{Al}_{2} \mathrm{O}_{3}$, and $\mathrm{B}_{4} \mathrm{C}$, the $\mathrm{B}_{4} \mathrm{C}$ particles exhibit the best reinforcing effect, while $\mathrm{Al}_{2} \mathrm{O}_{3}$ particles exhibit the worst one.
Recently, FSP can also be employed to produce Mgbased SMMCs for biomedical use. For instance, Sunil et al. [100, 125] used FSP to add hydroxyapatite into pure $\mathrm{Mg}$ and AZ31 Mg alloy. It showed that the SMMCs prepared by FSP had excellent bioactivity, degradation rate, and cell adhesion properties. In addition, the hydroxyapatite had a pinning effect on the grain boundaries, which resulted in grain refinement. Similarly, Hanas et al. [124] used FSP to prepare hydroxyapatite-enhanced AZ31 SMMCs to obtain higher biological activity. Qin et al. [123] used two-pass FSP to add hydroxyapatite to the ZK60 Mg alloy to promote uniform dispersion of hydroxyapatite. The so-prepared SMMCs showed improved corrosion resistance. Therefore, developing FSP to prepare biomedical Mg-based SMMCs is a promising research direction.

\subsection{FSP Additive Manufacturing}

Additive manufacturing is a process of joining materials to make objects from 3D model data, rather than subtractive manufacturing such as machining technology. The conventional additive manufacturing technology for $\mathrm{Mg}$ alloys mainly includes laser cladding [129] and selective laser melting [130], which are based on high-energy beam as the heat source to melt and solidify the metal layer by layer. However, there are solidification defects in the metals prepared by using the above-mentioned technologies. Furthermore, the static and dynamic mechanical properties of the prepared metals are low, which cannot be compared with forgings. Moreover, traditional additive manufacturing technology cannot realize the additive manufacturing of light metals, such as $\mathrm{Al}$ and $\mathrm{Mg}$ alloys, due to their high reflectivity.

To solve the problem of traditional additive manufacturing technology for Mg alloys, Schultz and Creehan [131] invented the FSP additive manufacturing technology, whose technical schematic is reported in Fig. 6. There, the raw materials of solid powder are in contact with the substrate through the tool with a hollow structure under the action of axial feed pressure and rub the substrate under the action of the rotating shoulder, resulting in severe plastic deformation. Thermoplastic materials are deposited on the substrate layer by layer along with the moving of the stir tool, which realizes the three-dimensional additive manufacturing. Figure 7 shows the products fabricated by using FSP additive manufacturing technology of the MELD manufacturing company [132].

Kandasamy et al. [133] prepared the bulk AZ31 Mg alloy from powder by using FSP additive manufacturing technology, proving that this technique can be successfully used to fabricate non-defective and dense bulk Mg alloys. During the additive manufacturing process, the alloy underwent severe plastic deformation, while the grains were 
Table 4 Brief summary of the work research carried out to produce FSPed Mg-based SMMCs as reported in the literature

\begin{tabular}{lll}
\hline Mg matrix & Reinforcing phase & Method of reinforcing particles \\
\hline Pure Mg [103]; & MWCNTs & Groove + covering [103, 118]; \\
AZ31 [99]; & & Groove [99]; \\
AZ91 [102]; & & Hole + melting + extrusion [102
\end{tabular}

$$
\text { RZ5 [118] }
$$

Hole + melting + extrusion [102]

Carbon fiber

AZ31 [126];

AZ91 [126, 127]

AZ31 [101];

AZ91 [105,106, 108-111];

ZM21 [107]

$\mathrm{SiC}$

AZ31 [112];

AZ61 [113]

AZ31 [114, 115];
AZ91 [106, 116, 117]

RZ5 [118];

ZM21 [107]

AZ31 [119, 120]

$\mathrm{TiC}$

Groove + covering [119];

Groove [120]

Groove + covering [107, 114-116];

Groove [117]

Groove + covering [118];

Hole + covering [107]

AZ31 [121]

$\mathrm{ZrO}_{2}$

Groove [121]
The secondary phase strengthening and finegrained strengthening of CNTs increase the microhardness of Mg-based SMMCs.

CNTs lead to the occurrence of galvanic corrosion and the decrease in corrosion resistance of pure $\mathrm{Mg}$.

Low traverse speed is beneficial to the uniform distribution of MWCNTs.

The elastic modulus, yield strength, and ultimate tensile strength increase, but the plasticity decreases

FSPed AZ91 Mg alloy has the characteristics of precipitation hardening and high hardness.

The addition of carbon fibers reduces the plasticity of Mg-based SMMCs

The uniform distribution of $\mathrm{SiC}$ particles improves the strength of AZ91 Mg alloy.

$\mathrm{SiC}$ particle-reinforced $\mathrm{AZ} 91 \mathrm{Mg}$ alloy has excellent friction and wear resistance.

The microstructure with the addition of nano$\mathrm{SiC}$ particles is more uniform than that with the addition of micron-SiC particles.

Increasing the number of FSP passes can promote the uniform distribution of $\mathrm{SiC}$ particles

The addition of nano- $\mathrm{SiO}_{2}$ particles leads to the grain refinement and the formation of equiaxed ultrafine-grained structure.

The hardness of Mg-based SMMCs reinforced by nano- $\mathrm{SiO}_{2}$ particles is increased by two times.

Multipass FSP promotes the uniform distribution of $\mathrm{SiO}_{2}$ particles

The distribution of $\mathrm{Al}_{2} \mathrm{O}_{3}$ particles is improved by increasing the rotational speed.

Grain refinement is promoted by the addition of $\mathrm{Al}_{2} \mathrm{O}_{3}$ particles.

Increasing the number of FSP passes can improve the uniformity of microstructure and refine grains

Grain refinement is promoted by the addition of $\mathrm{B}_{4} \mathrm{C}$ particles.

$\mathrm{B}_{4} \mathrm{C}$ particles promote wear resistance, due to grain boundary pinning and dispersion hardening

TiC particles are uniformly distributed in the AZ31 Mg alloy matrix without agglomeration and interfacial reaction.

TiC particles promote the grain refinement and the increase in microhardness

The addition of $\mathrm{ZrO}_{2}$ promotes the grain refinement and improves the strength and hardness of Mg-based SMMCs.

Increasing the number of FSP passes reduces the particle agglomeration, promotes the grain refinement, and enhances the pinning effect of the particles 
Table 4 (continued)

\begin{tabular}{|c|c|c|c|}
\hline Mg matrix & Reinforcing phase & Method of reinforcing particles introduction & Findings \\
\hline $\begin{array}{l}\text { Pure Mg [104]; } \\
\text { AZ31 [104] }\end{array}$ & $\mathrm{Mg}-18.8 \% \mathrm{Gd}-2 \% \mathrm{BN}$ & Groove + covering $[104]$ & $\begin{array}{l}\text { The particles agglomerate and present } \\
\text { streamlined distribution in pure } \mathrm{Mg} \text {, while } \\
\text { uniformly distributed in AZ31. } \\
\text { The particle agglomeration leads to a doubling } \\
\text { of microhardness in pure } \mathrm{Mg} \text {. } \\
\text { The addition of particles promotes the grain } \\
\text { refinement and improves the strength and } \\
\text { hardness of AZ31 }\end{array}$ \\
\hline AZ31 [122] & Fly ash & Groove [122] & $\begin{array}{l}\text { The addition of fly ash particles promotes the } \\
\text { grain refinement and improves the micro- } \\
\text { hardness }\end{array}$ \\
\hline $\begin{array}{l}\text { ZK60 [123]; } \\
\text { AZ31 [124] }\end{array}$ & Hydroxyapatite & Groove + covering $[123,124]$ & $\begin{array}{l}\text { Reverse second pass of FSP is beneficial to the } \\
\text { uniform distribution of nano-hydroxyapatite. } \\
\text { The addition of nano-hydroxyapatite particles } \\
\text { improves the corrosion resistance. } \\
\text { Nano-hydroxyapatite promotes the grain } \\
\text { refinement. } \\
\text { AZ31/nano-hydroxyapatite composite material } \\
\text { prepared by FSP has high biological activity. } \\
\text { Acid treatment of AZ31/nano-hydroxyapatite } \\
\text { composite material facilitates the decrease } \\
\text { in the degradation rate, promoting biominer- } \\
\text { alization }\end{array}$ \\
\hline AZ31 [128] & Stainless steel & Groove [128] & $\begin{array}{l}\text { The } \mathrm{Mg} \text { alloy reinforced by } 304 \text { stainless steel } \\
\text { powders has good tensile strength, hardness, } \\
\text { corrosion resistance, and wear resistance }\end{array}$ \\
\hline
\end{tabular}

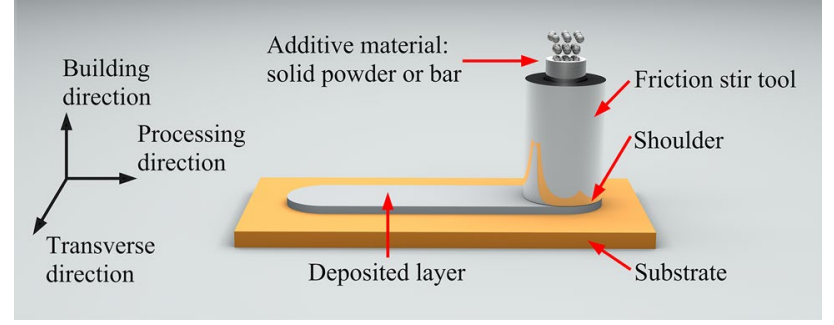

Fig. 6 Schematic of FSP additive manufacturing technology. $B D$ building direction

significantly refined, showing the typical microstructure of FSP. The hardness of the bulk AZ31 Mg alloy was comparable to that of the BM; the ultimate tensile strengths along the $\mathrm{PD}, \mathrm{TD}$, and BD were 254,264 , and $333 \mathrm{MPa}$, respectively, reaching $96 \%, 98 \%$, and $114 \%$ of those of the corresponding directions of the BM.

Calvert [134] used solid powder and bar as raw materials to prepare bulk WE43 Mg alloy by FSP additive manufacturing technology. The well-formed bulk $\mathrm{Mg}$ alloys were obtained without macroscopic defects such as pores and cracks. Compared with the initial bar, the grain size of the prepared bulk Mg alloys was refined from $15 \mu \mathrm{m}$ of the raw materials to $2.0-2.4 \mu \mathrm{m}$, whereas the elongation was increased by $22.5 \%$ and $200 \%$ for the powder filler and the bar filler, respectively. The ultimate tensile strengths along the PD, TD, and BD were 287, 295, and $290 \mathrm{MPa}$ (powder filler), and 280, 285, and $275 \mathrm{MPa}$ (bar filler), respectively, indicating that there was no significant anisotropy in bulk Mg alloys.

The above-mentioned studies show that FSP additive manufacturing is a promising method for fabricating bulk $\mathrm{Mg}$ alloys with excellent mechanical properties, such as low residual deformation, homogeneous and dense microstructure.

\section{Summary and Prospect}

FSP, as a severe plastic deformation technique, exhibits great advantages in the modification of the cast structure, superplastic deformation, preparation of fine-grained $\mathrm{Mg}$ alloys and Mg-based SMMCs, and additive manufacturing. The summary and prospect in research and application of FSP are as follows:

(1) FSP can modify the cast structure of Mg alloys, leading to the break and rapid dissolution of network-like secondary phases, thus decreasing the composition segregation. Moreover, the duplex process of FSP and postaging heat treatment is an effective method to improve the mechanical properties of precipitation-strengthened $\mathrm{Mg}$ alloys. In addition, FSP is also an effective method 

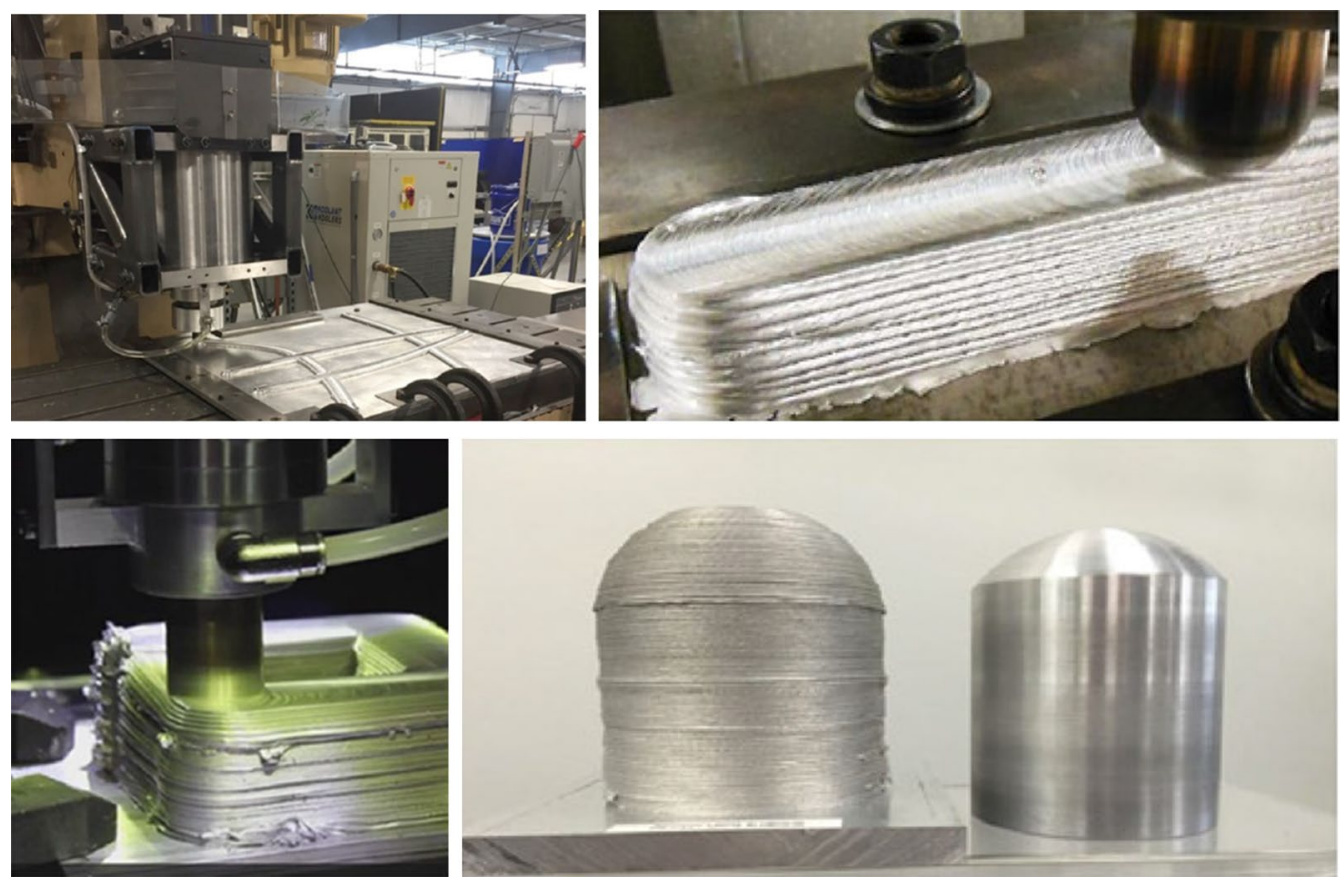

Fig. 7 Products fabricated by using FSP additive manufacturing technology of the MELD manufacturing company [132]

combination to repair the microstructure of fusionwelded joints of $\mathrm{Mg}$ alloys, therefore improving their strength. In the future, it is important to focus on how to enhance the engineering application of FSP in the surface defect repair of cast $\mathrm{Mg}$ alloys.

(2) FSP can be used to prepare fine-, ultrafine-, and even nano-grained $\mathrm{Mg}$ alloys. The main reason for grain refinement is the dynamic recrystallization during FSP. The recrystallization mechanism includes continuous dynamic recrystallization, discontinuous dynamic recrystallization, and twinning-induced recrystallization. Fine-grained $\mathrm{Mg}$ alloys prepared by FSP show low sensitivity of fine-grain strengthening due to shear texture. Therefore, it is necessary to study the relationship between texture and mechanical, corrosion, and biological properties. In the future, the stability of FSP should be further controlled, while the modification area should be expanded in order to prepare bulk mass fine-grained Mg alloys.

(3) The microcrystalline superplasticity, HSRS, and LTSP of Mg alloys prepared by FSP can be achieved. It is generally believed that the superplastic deformation mechanism of FSPed Mg alloys is the multimechanism dominated by GBS. The coordination mechanism of GBS in FSPed Mg alloys includes grain boundary diffusion, dislocation slip, and creep. Future research efforts should focus on how to accelerate the application of FSP in the whole or selection superplastic forming of $\mathrm{Mg}$ alloys.
(4) The Mg-based SMMCs can be successfully prepared by FSP, with the reinforcing particles mainly including CNTs, carbon fiber, $\mathrm{SiC}, \mathrm{SiO}_{2}, \mathrm{Al}_{2} \mathrm{O}_{3}, \mathrm{~B} 4 \mathrm{C}, \mathrm{TiC}, \mathrm{ZrO}_{2}$, fly ash, hydroxyapatite, and stainless steel powder. The agglomeration and uniform distribution of reinforcing particles can be improved by increasing the number of processing passes. The surface hardness, tensile strength, and wear resistance of Mg alloys are improved by adding reinforcing particles. Dispersion strengthening and fine-grained strengthening are the main mechanisms for the improvement in mechanical properties of Mg-based SMMCs. The following challenges are worth paying attention to in the future: firstly, to prepare the complex and irregular Mg-based SMMCs; secondly, to accurately control the amount of reinforcing particles; and thirdly, to improve the uniformity of reinforcing particles.

(5) FSP additive manufacturing is a prospective method for fabricating bulk Mg alloys with excellent mechanical properties, such as low residual deformation, homogeneous and dense microstructure. However, the research on FSP additive manufacturing technique on $\mathrm{Mg}$ alloys has been just initiated as there are some shortcomings in the design, process, equipment, as well as theoretical considerations. It is necessary to carry out a systematic study on the relations between design, process parameters, microstructure, and properties. Equally important is to develop FSP additive manufacturing equipment and realize its engineering application. 
(6) In addition to fabricating high-performance structural materials, FSP can also be used to prepare functional materials, such as gradient functional materials, biomedical materials, and hydrogen-storage materials. Therefore, in the future research efforts, researchers should actively explore new application fields for FSP.

Acknowledgements The authors gratefully acknowledge the sponsorship from the National Natural Science Foundation of China (Nos. 51574192, 51404180, 51974220, and U1760201); the Key Industrial Research Program of Shaanxi Province, China (No. 2017ZDXMGY-037); the National Key Research and Development Program of China (No. Z20180407); and the Youth Innovation Team of Shaanxi Universities (No. 2019-2022).

\section{References}

[1] B.L. Mordike, T. Ebert, Mater. Sci. Eng. A 302, 37 (2001)

[2] Q. Liu, Acta Metall. Sin. (Engl. Lett.) 46, 1458 (2010)

[3] R.S. Mishra, Z.Y. Ma, Mater. Sci. Eng. R 50, 1 (2005)

[4] J.Q. Su, T.W. Nelson, C.J. Sterling, Mater. Sci. Eng. A 405, 277 (2005)

[5] D.C. Hofmann, K.S. Vecchio, Mater. Sci. Eng. A 402, 234 (2005)

[6] C.I. Chang, X.H. Du, J.C. Huang, Scr. Mater. 57, 209 (2007)

[7] I. Charit, R.S. Mishra, Mater. Sci. Eng. A 359, 290 (2003)

[8] G.K. Padhy, C.S. Wu, S. Gao, J. Mater. Sci. Technol. 34, 1 (2018)

[9] A.H. Feng, Z.Y. Ma, Scr. Mater. 56, 397 (2007)

[10] Z.Y. Ma, B.L. Xiao, J. Yang, A.H. Feng, Mater. Sci. Forum 638-642, 1191 (2010)

[11] K.S. Wang, W. Wang, W. Guo, W.L. Wang, J.L. Wu, Rare Met. Mater. Eng. 39, 1275 (2010)

[12] M. Sabbaghian, R. Mahmudi, J. Mater. Eng. Perform. 25, 1856 (2016)

[13] Z.Y. Ma, A.L. Pilchak, M.C. Juhas, J.C. Williams, Scr. Mater. 58, 361 (2008)

[14] W. Wang, K.S. Wang, Q. Guo, N. Wu, Rare Met. Mater. Eng. 41, $1522(2012)$

[15] B. Hassani, R. Vallant, F. Karimzadeh, M.H. Enayati, S. Sabooni, K. Pradeep, Surf. Rev. 26, 1850213 (2019)

[16] J. Lin, T.Z. Da, Z. Wen, Q. Cheng, Mater. Sci. Forum 898, 278 (2017)

[17] B.L. Xiao, Q. Yang, J. Yang, W.G. Wang, G.M. Xie, Z.Y. Ma, J. Alloys Compd. 509, 2879 (2011)

[18] Q. Yang, B.L. Xiao, Z.Y. Ma, Metall. Mater. Trans. A 43, 2094 (2012)

[19] F.Y. Zheng, L.M. Peng, Y.J. Wu, X.W. Li, Y. Zhang, W.J. Ding, Mater. Sci. Forum 765, 726 (2013)

[20] Q. Yang, B.L. Xiao, D. Wang, M.Y. Zheng, K. Wu, Z.Y. Ma, J. Alloys Compd. 581, 585 (2013)

[21] V. Jain, J.Q. Su, R.S. Mishra, R. Verma, A. Javaid, M. Aljarrah, E. Essadiqi, Magnes. Technol. 1133, 565 (2016)

[22] A. Afrinaldi, T. Kakiuchi, R. Itoh, Y. Mizutani, Y. Uematsu, Int. J. Adv. Manuf. Technol. 95, 2379 (2018)

[23] Y.Y. Jin, K.S. Wang, W. Wang, P. Peng, S. Zhou, L.Y. Huang, T. Yang, K. Qiao, B. Zhang, J. Cai, H.L. Yu, Mater. Charact. 150, $52(2019)$

[24] N. Xu, Y.F. Bao, Mater. Sci. Eng. A 655, 292 (2016)

[25] N. Kumar, R.S. Mishra, N.B. Dahotre, R.E. Brennan, K.J. Doherty, K.C. Cho, Mater. Des. 110, 663 (2016)

[26] G.M. Karthik, G.D. Janaki Ram, R.S. Kottada, Metall. Mater. Trans. B 48, 3270 (2017)
[27] A.H. Feng, Z.Y. Ma, Acta Mater. 57, 4248 (2009)

[28] L.H. Wu, X.B. Hu, X.X. Zhang, Y.Z. Li, Z.Y. Ma, X.L. Ma, B.L. Xiao, Acta Mater. 166, 371 (2019)

[29] X.H. Zeng, P. Xue, L.H. Wu, D.R. Ni, B.L. Xiao, K.S. Wang, Z.Y. Ma, J. Mater. Sci. Technol. 35, 972 (2019)

[30] F. Chai, D.T. Zhang, Y.Y. Li, Materials 7, 1573 (2014)

[31] F. Chai, D.T. Zhang, Y.Y. Li, W. Zhang, J. Mater. Sci. 50, 3212 (2015)

[32] M. Fairman, N. Afrin, D.L. Chen, X. Cao, M. Jahazi, Can. Metall. Q. 46, 425 (2007)

[33] F.Y. Hung, C.C. Shih, L.H. Chen, T.S. Lui, J. Alloys Compd. 428, 106 (2007)

[34] X.H. Du, E.L. Zhang, B.L. Wu, Int. J. Mater. Res. 99, 1375 (2008)

[35] X.H. Du, B.L. Wu, Trans. Nonferrous Met. Soc. China 18, 562 (2008)

[36] X.H. Du, B.L. Wu, Sci. China Technol. Sci. 52, 1751 (2009)

[37] G.M. Xie, Z.Y. Ma, Z.A. Luo, P. Xue, G.D. Wang, J. Mater. Sci. Technol. 27, 1157 (2011)

[38] B.M. Darras, J. Mater. Eng. Perform. 21, 1243 (2012)

[39] B. Darras, E. Kishta, Mater. Des. 47, 133 (2013)

[40] H.S. Arora, H.S. Grewal, H. Singh, B.K. Dhindaw, S. Mukherjee, Adv. Eng. Mater. 16, 571 (2014)

[41] F. Chai, D.T. Zhang, Y.Y. Li, Mater. Res. Innov. 18, 152 (2014)

[42] C.I. Chang, X.H. Du, J.C. Huang, Scr. Mater. 59, 356 (2008)

[43] J.A. Del Valle, P. Rey, D. Gesto, D. Verdera, J.A. Jiménez, O.A. Ruano, Mater. Sci. Eng. A 628, 198 (2015)

[44] L.Y. Huang, K.S. Wang, W. Wang, J. Yuan, K. Qiao, T. Yang, P. Peng, T.Q. Li, Eng. Fail. Anal. 92, 392 (2018)

[45] W. Woo, H. Choo, D.W. Brown, P.K. Liaw, Z. Feng, Scr. Mater. 54, 1859 (2006)

[46] W. Yuan, R.S. Mishra, B. Carlson, R.K. Mishra, R. Verma, R. Kubic, Scr. Mater. 64, 580 (2011)

[47] Z.Z. Yu, H. Choo, Z.L. Feng, S.C. Vogel, Scr. Mater. 63, 1112 (2010)

[48] N.Y. Wang, I.C. Chang, J.C. Lee, K.H. Lin, C.J. Huang, Scr. Mater. 55, 637 (2006)

[49] W. Yuan, S.K. Panigrahi, J.Q. Su, R.S. Mishra, Scr. Mater. 65, 994 (2011)

[50] M.F. Yu, in Relationship Between Grain Size and Mechanical Properties of Friction Stir Processing AZ31 Magnesium Alloy, M.D. Thesis, Xi' an University of Archtecture and Technology, 2014. (in Chinese)

[51] Y. Wang, H. Choo, Acta Mater. 81, 83 (2014)

[52] L.L. Guo, Z.C. Chen, L. Gao, Mater. Sci. Eng. A 528, 8537 (2011)

[53] Y. Chino, M. Mabuchi, R. Kishihara, H. Hosokawa, Y. Yamada, C. Wen, K. Shimojima, H. Iwasaki, Mater. Trans. 43, 2554 (2002)

[54] A. Jain, O. Duygulu, D.W. Brown, C.N. Tomé, S.R. Agnew, Mater. Sci. Eng. A 486, 545 (2008)

[55] L.L. Chang, Y.N. Wang, X. Zhao, M. Qi, Mater. Charact. 60 , 991 (2009)

[56] Y. Yoshida, L. Cisar, S. Kamado, Y. Kojima, Mater. Trans. 44, $468(2003)$

[57] S.R. Agnew, Ö. Duygulu, Int. J. Plast. 21, 1161 (2005)

[58] W.J. Kim, H.T. Jeong, Mater. Trans. 46, 251 (2005)

[59] H.K. Kim, Mater. Sci. Eng. A 515, 66 (2009)

[60] J.A.D. Valle, F. Carreño, O.A. Ruano, Acta Mater. 54, 4247 (2006)

[61] J.T. Wang, D.L. Yin, J.Q. Liu, J. Tao, Y.L. Su, X. Zhao, Scr. Mater. 59, 63 (2008)

[62] Y.N. Wang, J.C. Huang, Mater. Trans. 48, 184 (2007)

[63] R.L. Xin, D.J. Liu, B. Li, L.Y. Sun, Z. Zhou, Q. Liu, Mater. Sci. Eng. A 565, 333 (2013) 
[64] F.Y. Zheng, Y.J. Wu, L.M. Peng, X.W. Li, P.H. Fu, W.J. Ding, J. Magnes, Alloys 1, 122 (2013)

[65] H. Zhang, H.Y. Wang, J.G. Wang, J. Rong, M. Zha, C. Wang, P.K. Ma, Q.C. Jiang, J. Alloys Compd. 780, 312 (2019)

[66] A. Raja, P. Biswas, V. Pancholi, Mater. Sci. Eng. A 725, 492 (2018)

[67] W. Yuan, R.S. Mishra, Mater. Sci. Eng. A 558, 716 (2012)

[68] Q. Shang, D.R. Ni, P. Xue, B.L. Xiao, K.S. Wang, Z.Y. Ma, J. Mater. Process. Technol. 264, 336 (2019)

[69] N. Xu, Q.N. Song, Y.F. Bao, Mater. Sci. Eng. A 745, 400 (2019)

[70] Z.Y. Ma, G.M. Xie, A.H. Feng, in Twelfth Annual Conference on Materials Science and Alloy Processing of Chinese Society of Nonferrous Metals, Zhangjiajie, Hebei Provience, China, 2007

[71] G.M. Xie, Z.Y. Ma, L. Geng, R.S. Chen, J. Mater. Res. 23, 1207 (2008)

[72] Y. Takayama, I. Takeda, T. Shibayanagi, H. Kato, K. Funami, Key Eng. Mater. 433, 241 (2010)

[73] D.T. Zhang, F. Xiong, W.W. Zhang, C. Qiu, W. Zhang, Trans. Nonferrous Met. Soc. China 21, 1911 (2011)

[74] Y.H. Wei, Q.D. Wang, M.P. Liu, W.J. Ding, Mater. Rev. 16, 20 (2002)

[75] F. Chai, D.T. Zhang, Y.Y. Li, W. Zhang, Mater. Sci. Eng. A 568, 40 (2013)

[76] Q. Yang, B.L. Xiao, Z.Y. Ma, R.S. Chen, Scr. Mater. 65, 335 (2011)

[77] A. Mohan, W. Yuan, R.S. Mishra, Mater. Sci. Eng. A 562, 69 (2013)

[78] D.T. Zhang, S.X. Wang, Q. Chen, W. Zhang, Mater. Sci. Eng. A 556, $100(2012)$

[79] Q. Yang, A.H. Feng, B.L. Xiao, Z.Y. Ma, Mater. Sci. Eng. A 556, 671 (2012)

[80] P. Cavaliere, P.P. De Marco, Mater. Sci. Eng. A 462, 393 (2007)

[81] V. Jain, R.S. Mishra, J. Mater. Sci. 48, 2635 (2013)

[82] V. Jain, R.S. Mishra, R. Verma, E. Essadiqi, Scr. Mater. 68, 447 (2013)

[83] X. Gao, Z. Zhang, W. Wang, M.N. Hai, S.W. Jia, K.S. Wang, Rare Met. Mater. Eng. 45, 1855 (2016)

[84] C.J. Lee, J.C. Huang, Mater. Trans. 47, 2773 (2006)

[85] S.X. Shang, Y.L. Guo, S.F. Liu, S.L. Wu, Adv. Mater. Res. 941944, 93 (2014)

[86] P. Cavaliere, P.P.D. Marco, J. Mater. Process. Technol. 184, 77 (2007)

[87] F. Chai, D.T. Zhang, W.W. Zhang, Y.Y. Li, Mater. Sci. Eng. A 590, $80(2014)$

[88] S.X. Wang, in Investigation on Fabrication, Microstructure and Mechanical Properties of Friction Stir Processed Fine-Grained Magnesium Alloys, M.D. Thesis, South China University of Technology, 2012. (in Chinese)

[89] G.M. Xie, Z.Y. Ma, P. Xue, Z.A. Luo, G.D. Wang, Acta Metall. Sin. 54, 1745 (2018)

[90] Q. Yang, B.L. Xiao, Z.Y. Ma, J. Alloys Compd. 551, 61 (2013)

[91] J. Li, D. Zhang, F. Chai, Mater. Res. Innov. 18, S4 (2014)

[92] G.H. Cao, D.T. Zhang, F. Chai, W. Zhang, C. Qiu, Adv. Eng. Mater. 18, 312 (2016)

[93] F. Khan, S.K. Panigrahi, J. Alloys Compd. 747, 71 (2018)

[94] O.A. Kaibyshev, I.V. Kazachkov, N.G. Zaripov, J. Mater. Sci. 23, 4369 (1988)

[95] H.K. Lin, J.C. Huang, T.G. Langdon, Mater. Sci. Eng. A 402, 250 (2005)

[96] J.A. Del Valle, O.A. Ruano, Acta Mater. 55, 455 (2007)

[97] R. Panicker, A.H. Chokshi, R.K. Mishra, R. Verma, P.E. Krajewski, Acta Mater. 57, 3683 (2009)

[98] Y.N. Wang, J.C. Huang, Mater. Trans. 44, 2276 (2003)

[99] Y. Morisada, H. Fujii, T. Nagaoka, M. Fukusumi, Mater. Sci. Eng. A 419, 344 (2006)

[100] B.R. Sunil, G.P. Kumar Reddy, H. Patle, R. Dumpala, J. Magnes. Alloys 4, 52 (2016)

[101] Y.X. Huang, T.H. Wang, W.Q. Guo, L. Wan, S.X. Lv, Mater. Des. 59, 274 (2014)
[102] J.H. Liang, H.J. Li, L.H. Qi, W.L. Tian, X.F. Li, X.J. Chao, J.F. Wei, J. Alloys Compd. 728, 282 (2017)

[103] N. Saikrishna, G. Pradeep Kumar Reddy, B. Munirathinam, R. Dumpala, M. Jagannatham, B.R. Sunil, J. Magnes. Alloys 6, 83 (2018)

[104] H.G. Liao, J. Chen, L.M. Peng, J.Y. Han, H. Yi, F.Y. Zheng, Y.J. Wu, W.J. Ding, Mater. Sci. Eng. A 683, 207 (2017)

[105] T.J. Chen, Z.M. Zhu, Y. Ma, Y.D. Li, Y. Hao, J. Wuhan Univ. Technol. Mater. Sci. Ed. 25, 223 (2010)

[106] P. Asadi, G. Faraji, A. Masoumi, M.K. Besharati Givi, Metall. Mater. Trans. A 42, 2820 (2011)

[107] G.M. Reddy, A.S. Rao, K.S. Rao, Trans. Indian Inst. Met. 66, 13 (2013)

[108] P. Asadi, M.K. Besharati Givi, A. Rastgoo, M. Akbari, V. Zakeri, S. Rasouli, Int. J. Adv. Manuf. Technol. 63, 1095 (2012)

[109] P. Asadi, M.K. Besharati Givi, G. Faraji, Mater. Manuf. Process. 25, 1219 (2010)

[110] P. Asadi, G. Faraji, M.K. Besharati, Int. J. Adv. Manuf. Technol. 51, 247 (2010)

[111] J. Iwaszko, K. Kudła, K. Fila, Arch. Mater. Sci. Eng. 77, 85 (2016)

[112] Y. Jiang, X. Yang, H. Miura, T. Sakai, Rev. Adv. Mater. Sci. 33, 29 (2013)

[113] C.J. Lee, J.C. Huang, P.J. Hsieh, Scr. Mater. 54, 1415 (2006)

[114] M. Azizieh, A.N. Larki, M. Tahmasebi, M. Bavi, E. Alizadeh, H.S. Kim, J. Mater. Eng. Perform. 27, 2010 (2018)

[115] M. Azizieh, A.H. Kokabi, P. Abachi, Mater. Des. 32, 2034 (2011)

[116] G. Faraji, O. Dastani, S.A.A.A. Mousavi, Proc. Inst. Mech. Eng. Part B 225, 1331 (2011)

[117] G. Faraji, S.A.A.A. Mousavi, J. Mater. Eng. Perform. 20, 1583 (2011)

[118] G. Vedabouriswaran, S. Aravindan, J. Magnes, Alloys 6, 145 (2018)

[119] M. Balakrishnan, I. Dinaharan, R. Palanivel, R. Sivaprakasam, J. Magnes, Alloys 3, 76 (2015)

[120] M. Navazani, K. Dehghani, Procedia Mater. Sci. 11, 509 (2015)

[121] M. Navazani, K. Dehghani, J. Mater. Process. Technol. 229, 439 (2016)

[122] I. Dinaharan, E.T. Akinlabi, Compos. Commun. 9, 22 (2018)

[123] D.Q. Qin, H.R. Shen, Z.K. Shen, H.Y. Chen, L. Fu, J. Manuf. Process. 36, 22 (2018)

[124] T. Hanas, T.S. Sampath Kumar, G. Perumal, M. Doble, S. Ramakrishna, J. Mater. Process. Technol. 252, 398 (2018)

[125] B.R. Sunil, T.S. Sampath Kumar, U. Chakkingal, V. Nandakumar, M. Doble, J. Mater. Sci. Mater. Med. 25, 975 (2014)

[126] A. Simar, A. Mertens, S. Ryelandt, F. Delannay, L. Brassart, Mater. Sci. Eng. A 723, 324 (2018)

[127] A. Mertens, A. Simar, F. Delannay, Mater. Sci. Forum 706-709, 1221 (2012)

[128] A. Adetunla, E. Akinlabi, Mater. Res. Express 6, 025406 (2019)

[129] Y.L. Gao, D.S. Xiong, C.S. Wang, Y.Z. Chen, Acta Metall. Sin. (Engl. Lett.) 22, 167 (2009)

[130] K. Wei, M. Gao, Z. Wang, X. Zeng, Mater. Sci. Eng. A 611, 212 (2014)

[131] J.P. Schultz, K. Creehan, Friction Fabrication Tools, US Patent, No. 20140121, 2014

[132] MELD Manufacturing (2019). http://meldmanufacturing.com/

[133] K. Kandasamy, L. Renaghan, J.R. Calvert, K. Creehan, J.P. Schultz, in Proceedings of the Materials science and technology Conference, Montreal, Qucbec, Canada, October 27-31, 2013

[134] J.R. Calvert, Microstructure and Mechanical Properties of WE43 Alloy Produced Via Additive Friction Stir Technology, M.D. Thesis, Virginia Polytechnic Institute and State University, 2015 